\title{
Prostate cancer risk stratification improved across multiple ancestries with new polygenic hazard score
}

\section{Corresponding Author:}

Tyler M. Seibert, MD, PhD

Assistant Professor

Department of Radiation Medicine and Applied Sciences

Department of Radiology

Department of Bioengineering

Center for Multimodal Imaging and Genetics

University of California San Diego

9500 Gilman Dr. Mail Code 0861

La Jolla, CA 92093-0861

tseibert@ucsd.edu

\section{Authors:}

Minh-Phuong Huynh-Le $e^{1,2,3}$

Roshan Karunamuni ${ }^{2,3}$

Chun Chieh Fan ${ }^{3}$

Lui Asona ${ }^{2}$

Wesley K Thompson ${ }^{4,5}$

Maria Elena Martinez ${ }^{6}$

Rosalind A Eeles 7,8

Zsofia Kote-Jarai $^{7}$

Kenneth R Muir ${ }^{9}$

Artitaya Lophatananon ${ }^{9}$

Johanna Schleutker ${ }^{10,11}$

Nora Pashayan ${ }^{12,13}$

Jyotsna Batra ${ }^{14,15}$

Henrik Grönberg ${ }^{16}$

David E Neal ${ }^{17,18,19}$

Børge G Nordestgaard ${ }^{20,21}$

Catherine M Tangen 22

Robert J MacInnis ${ }^{23,24}$

Alicja Wolk ${ }^{25}$

Demetrius Albanes ${ }^{26}$

Christopher A Haiman ${ }^{27}$

Ruth C Travis ${ }^{28}$

William J Blot ${ }^{29,30}$

Janet L Stanford ${ }^{31,32}$

Lorelei A Mucci ${ }^{33}$

Catharine M L West ${ }^{34}$

Sune F Nielsen ${ }^{21,20}$ 


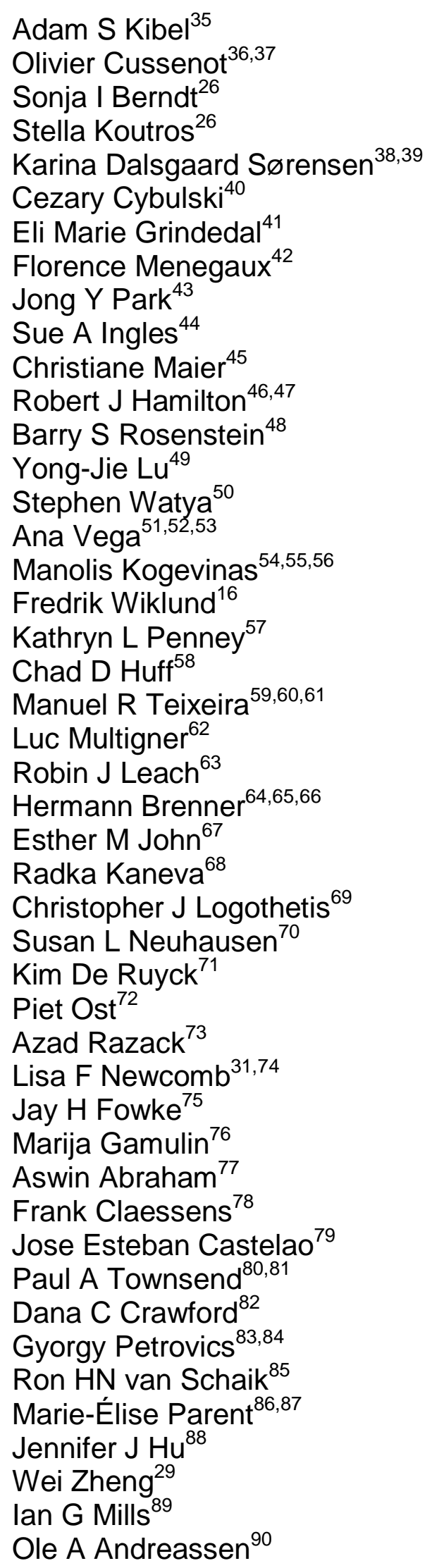


Anders M Dale ${ }^{91,3,90}$

Tyler M Seibert $2,3,91,92,90$

\section{Contributing consortia:}

UKGPCS collaborators ${ }^{93}$

APCB (Australian Prostate Cancer BioResource) $)^{94,95}$

NC-LA PCaP Investigators ${ }^{96}$

The IMPACT Study Steering Committee and Collaborators ${ }^{97}$

Canary PASS Investigators ${ }^{31,74}$

The Profile Study Steering Committee ${ }^{98}$

The PRACTICAL Consortium ${ }^{99}$

\section{Author affiliations:}

${ }^{1}$ Radiation Oncology, George Washington University, Washington, DC, USA

${ }^{2}$ Department of Radiation Medicine and Applied Sciences, University of California San Diego, La Jolla, CA, USA

${ }^{3}$ Center for Multimodal Imaging and Genetics, University of California San Diego, La Jolla, CA, USA

${ }^{4}$ Division of Biostatistics and Halicioğlu Data Science Institute, University of California San Diego

${ }^{5}$ Department of Family Medicine and Public Health, University of California San Diego

${ }^{6}$ University of California San Diego, Moores Cancer Center, Department of Family Medicine and Public Health, University of California San Diego, La Jolla, CA 920930012, USA

${ }^{7}$ The Institute of Cancer Research, London, SM2 5NG, UK

${ }^{8}$ Royal Marsden NHS Foundation Trust, London, SW3 6JJ, UK

${ }^{9}$ Division of Population Health, Health Services Research and Primary Care, University of Manchester, Oxford Road, Manchester, M13 9PL, UK

${ }^{10}$ Institute of Biomedicine, University of Turku, Finland

${ }^{11}$ Department of Medical Genetics, Genomics, Laboratory Division, Turku University Hospital, PO Box 52, 20521 Turku, Finland

${ }^{12}$ Department of Applied Health Research, University College London, London, WC1E 7HB, UK

${ }^{13}$ Centre for Cancer Genetic Epidemiology, Department of Oncology, University of Cambridge, Strangeways Laboratory, Worts Causeway, Cambridge, CB1 8RN, UK

${ }^{14}$ Australian Prostate Cancer Research Centre-Qld, Institute of Health and Biomedical Innovation and School of Biomedical Sciences, Queensland University of Technology, Brisbane QLD 4059, Australia

${ }^{15}$ Translational Research Institute, Brisbane, Queensland 4102, Australia

${ }^{16}$ Department of Medical Epidemiology and Biostatistics, Karolinska Institute, SE-171

77 Stockholm, Sweden

${ }^{17}$ Nuffield Department of Surgical Sciences, University of Oxford, Room 6603, Level 6, John Radcliffe Hospital, Headley Way, Headington, Oxford, OX3 9DU, UK

${ }^{18}$ University of Cambridge, Department of Oncology, Box 279, Addenbrooke's Hospital, Hills Road, Cambridge CB2 0QQ, UK 
medRxiv preprint doi: https://doi.org/10.1101/2021.08.14.21261931; this version posted August 18, 2021. The copyright holder for this preprint (which was not certified by peer review) is the author/funder, who has granted medRxiv a license to display the preprint in perpetuity. All rights reserved. No reuse allowed without permission.

${ }^{19}$ Cancer Research UK, Cambridge Research Institute, Li Ka Shing Centre, Cambridge, CB2 ORE, UK

${ }^{20}$ Faculty of Health and Medical Sciences, University of Copenhagen, 2200

Copenhagen, Denmark

${ }^{21}$ Department of Clinical Biochemistry, Herlev and Gentofte Hospital, Copenhagen

University Hospital, Herlev, 2200 Copenhagen, Denmark

${ }^{22}$ SWOG Statistical Center, Fred Hutchinson Cancer Research Center, Seattle, WA, USA

${ }^{23}$ Cancer Epidemiology Division, Cancer Council Victoria, 615 St Kilda Road, Melbourne, VIC 3004, Australia

${ }^{24}$ Centre for Epidemiology and Biostatistics, Melbourne School of Population and Global Health, The University of Melbourne, Grattan Street, Parkville, VIC 3010, Australia

${ }^{25}$ Department of Surgical Sciences, Uppsala University, 75185 Uppsala, Sweden

${ }^{26}$ Division of Cancer Epidemiology and Genetics, National Cancer Institute, NIH, Bethesda, Maryland, 20892, USA

${ }^{27}$ Center for Genetic Epidemiology, Department of Preventive Medicine, Keck School of Medicine, University of Southern California/Norris Comprehensive Cancer Center, Los Angeles, CA 90015, USA

${ }^{28}$ Cancer Epidemiology Unit, Nuffield Department of Population Health, University of Oxford, Oxford, OX3 7LF, UK

${ }^{29}$ Division of Epidemiology, Department of Medicine, Vanderbilt University Medical Center, 2525 West End Avenue, Suite 800, Nashville, TN 37232 USA.

${ }^{30}$ International Epidemiology Institute, Rockville, MD 20850, USA

${ }^{31}$ Division of Public Health Sciences, Fred Hutchinson Cancer Research Center, Seattle, Washington, 98109-1024, USA

${ }^{32}$ Department of Epidemiology, School of Public Health, University of Washington, Seattle, Washington 98195, USA

${ }^{33}$ Department of Epidemiology, Harvard T. H. Chan School of Public Health, Boston, MA 02115, USA

${ }^{34}$ Division of Cancer Sciences, University of Manchester, Manchester Academic Health Science Centre, Radiotherapy Related Research, The Christie Hospital NHS

Foundation Trust, Manchester, M13 9PL UK

${ }^{35}$ Division of Urologic Surgery, Brigham and Womens Hospital, 75 Francis Street, Boston, MA 02115, USA

${ }^{36}$ Sorbonne Universite, GRC n5 , AP-HP, Tenon Hospital, 4 rue de la Chine, F-75020 Paris, France

${ }^{37}$ CeRePP, Tenon Hospital, F-75020 Paris, France.

${ }^{38}$ Department of Molecular Medicine, Aarhus University Hospital, Palle Juul-Jensen Boulevard 99, 8200 Aarhus N, Denmark

${ }^{39}$ Department of Clinical Medicine, Aarhus University, DK-8200 Aarhus N

${ }^{40}$ International Hereditary Cancer Center, Department of Genetics and Pathology, Pomeranian Medical University, 70-115 Szczecin, Poland

${ }^{41}$ Department of Medical Genetics, Oslo University Hospital, 0424 Oslo, Norway

${ }^{42}$ Exposome and Heredity, CESP (UMR 1018), Faculté de Médecine, Université ParisSaclay, Inserm, Gustave Roussy, Villejuif 
medRxiv preprint doi: https://doi.org/10.1101/2021.08.14.21261931; this version posted August 18, 2021. The copyright holder for this preprint (which was not certified by peer review) is the author/funder, who has granted medRxiv a license to display the preprint in perpetuity. All rights reserved. No reuse allowed without permission.

${ }^{43}$ Department of Cancer Epidemiology, Moffitt Cancer Center, 12902 Magnolia Drive, Tampa, FL 33612, USA

${ }^{44}$ Department of Preventive Medicine, Keck School of Medicine, University of Southern California/Norris Comprehensive Cancer Center, Los Angeles, CA 90015, USA

${ }^{45}$ Humangenetik Tuebingen, Paul-Ehrlich-Str 23, D-72076 Tuebingen, Germany

${ }^{46}$ Dept. of Surgical Oncology, Princess Margaret Cancer Centre, Toronto ON M5G 2M9, Canada

${ }^{47}$ Dept. of Surgery (Urology), University of Toronto, Canada

${ }^{48}$ Department of Radiation Oncology and Department of Genetics and Genomic Sciences, Box 1236, Icahn School of Medicine at Mount Sinai, One Gustave L. Levy Place, New York, NY 10029, USA

${ }^{49}$ Centre for Cancer Biomarker and Biotherapeutics, Barts Cancer Institute, Queen Mary University of London, John Vane Science Centre, Charterhouse Square, London, EC1M 6BQ, UK

${ }^{50}$ Uro Care, Kampala, Uganda

${ }^{51}$ Fundación Pública Galega Medicina Xenómica, Santiago de Compostela, 15706, Spain.

${ }^{52}$ Instituto de Investigación Sanitaria de Santiago de Compostela, Santiago De Compostela, 15706, Spain.

${ }^{53}$ Centro de Investigación en Red de Enfermedades Raras (CIBERER), Spain

${ }^{54}$ ISGlobal, Barcelona, Spain

${ }^{5}$ IMIM (Hospital del Mar Medical Research Institute), Barcelona, Spain

${ }^{56}$ Universitat Pompeu Fabra (UPF), Barcelona, Spain

${ }^{57}$ Channing Division of Network Medicine, Department of Medicine, Brigham and Women's Hospital/Harvard Medical School, Boston, MA 02115, USA

${ }^{58}$ Department of Epidemiology, The University of Texas MD Anderson Cancer Center, 1515 Holcombe Blvd., Houston, TX 77030, USA

${ }^{59}$ Department of Genetics, Portuguese Oncology Institute of Porto (IPO-Porto), 4200072 Porto, Portugal

${ }^{60}$ Biomedical Sciences Institute (ICBAS), University of Porto, 4050-313 Porto, Portugal

${ }^{61}$ Cancer Genetics Group, IPO-Porto Research Center (CI-IPOP), Portuguese Oncology Institute of Porto (IPO-Porto), 4200-072 Porto, Portugal

${ }^{62}$ Univ Rennes, Inserm, EHESP, Irset (Institut de recherche en santé, environnement et travail) - UMR_S 1085, Rennes, France

${ }^{63}$ Department of Cell Systems and Anatomy, Mays Cancer Center, University of Texas Health Science Center at San Antonio, San Antonio Texas

${ }^{64}$ Division of Clinical Epidemiology and Aging Research, German Cancer Research Center (DKFZ), D-69120, Heidelberg, Germany

${ }^{65}$ German Cancer Consortium (DKTK), German Cancer Research Center (DKFZ), D69120 Heidelberg, Germany

${ }^{66}$ Division of Preventive Oncology, German Cancer Research Center (DKFZ) and National Center for Tumor Diseases (NCT), Im Neuenheimer Feld 460, 69120 Heidelberg, Germany

${ }^{67}$ Departments of Epidemiology \& Population Health and of Medicine, Division of Oncology, Stanford Cancer Institute, Stanford University School of Medicine, Stanford, CA 94304 USA 
medRxiv preprint doi: https://doi.org/10.1101/2021.08.14.21261931; this version posted August 18, 2021. The copyright holder for this preprint (which was not certified by peer review) is the author/funder, who has granted medRxiv a license to display the preprint in perpetuity. All rights reserved. No reuse allowed without permission.

${ }^{68}$ Molecular Medicine Center, Department of Medical Chemistry and Biochemistry, Medical University of Sofia, Sofia, 2 Zdrave Str., 1431 Sofia, Bulgaria

${ }^{69}$ The University of Texas M. D. Anderson Cancer Center, Department of Genitourinary Medical Oncology, 1515 Holcombe Blvd., Houston, TX 77030, USA

${ }^{70}$ Department of Population Sciences, Beckman Research Institute of the City of Hope, 1500 East Duarte Road, Duarte, CA 91010

${ }^{71}$ Ghent University, Faculty of Medicine and Health Sciences, Basic Medical Sciences, Proeftuinstraat 86, B-9000 Gent

${ }^{72}$ Ghent University Hospital, Department of Radiotherapy, De Pintelaan 185, B-9000, Gent, Belgium

${ }^{73}$ Department of Surgery, Faculty of Medicine, University of Malaya, 50603 Kuala Lumpur, Malaysia

${ }^{74}$ Department of Urology, University of Washington, 1959 NE Pacific Street, Box 356510, Seattle, WA 98195, USA

${ }^{75}$ Division of Epidemiology, Department of Preventive Medicine, University of

Tennessee Health Science Center, Memphis, TN 38163

${ }^{76}$ Department of Oncology, University Hospital Centre Zagreb, University of Zagreb, School of Medicine, 10000 Zagreb, Croatia

${ }^{77}$ Department of Oncology, Cross Cancer Institute, University of Alberta, 11560 University Avenue, Edmonton, Alberta, Canada T6G $1 Z 2$

${ }^{78}$ Molecular Endocrinology Laboratory, Department of Cellular and Molecular Medicine, KU Leuven, BE-3000, Belgium

${ }^{79}$ Genetic Oncology Unit, CHUVI Hospital, Complexo Hospitalario Universitario de Vigo, Instituto de Investigación Biomédica Galicia Sur (IISGS), 36204, Vigo (Pontevedra),

Spain

${ }^{80}$ Division of Cancer Sciences, Manchester Cancer Research Centre, Faculty of Biology, Medicine and Health, Manchester Academic Health Science Centre, NIHR Manchester Biomedical Research Centre, Health Innovation Manchester, Univeristy of Manchester, M13 9WL

${ }^{81}$ The University of Surrey, Guildford, Surrey, GU2 7XH, UK

${ }^{82}$ Case Western Reserve University, Department of Population and Quantitative Health Sciences, Cleveland Institute for Computational Biology, 2103 Cornell Road, Wolstein Research Building, Suite 2527, Cleveland, OH, 44106 USA

${ }^{83}$ Uniformed Services University, 4301 Jones Bridge Rd, Bethesda, MD 20814, USA

${ }^{84}$ Center for Prostate Disease Research, 6720A Rockledge Drive, Suite 300, Bethesda, MD 20817, USA

${ }^{85}$ Department of Clinical Chemistry, Erasmus University Medical Center, 3015 CE Rotterdam, The Netherlands

${ }^{86}$ Epidemiology and Biostatistics Unit, Centre Armand-Frappier Santé Biotechnologie, Institut national de la recherche scientifique, 531 Boul. des Prairies, Laval, QC, Canada H7V 1B7

${ }^{87}$ Department of Social and Preventive Medicine, School of Public Health, University of Montreal, Montreal, QC, Canada

${ }^{88}$ The University of Miami School of Medicine, Sylvester Comprehensive Cancer Center, 1120 NW 14th Street, CRB 1511, Miami, Florida 33136, USA

${ }^{89}$ Nuffield Department of Surgical Sciences, University of Oxford, Oxford, UK 
medRxiv preprint doi: https://doi.org/10.1101/2021.08.14.21261931; this version posted August 18, 2021. The copyright holder for this preprint (which was not certified by peer review) is the author/funder, who has granted medRxiv a license to display the preprint in perpetuity. All rights reserved. No reuse allowed without permission.

${ }^{90}$ NORMENT, KG Jebsen Centre, Oslo University Hospital and University of Oslo, Oslo, Norway

${ }^{91}$ Department of Radiology, University of California San Diego, La Jolla, CA, USA

${ }^{92}$ Department of Bioengineering, University of California San Diego, La Jolla, CA, USA

${ }^{93} \mathrm{http}: / /$ www.icr.ac.uk/our-research/research-divisions/division-of-genetics-andepidemiology/oncogenetics/research-projects/ukgpcs/ukgpcs-collaborators

${ }^{94}$ Australian Prostate Cancer Research Centre-Qld, Queensland University of Technology, Brisbane; Prostate Cancer Research Program, Monash University, Melbourne; Dame Roma Mitchell Cancer Centre, University of Adelaide, Adelaide; Chris O'Brien Lifehouse and The Kinghorn Cancer Centre, Sydney, Australia

${ }^{95}$ Translational Research Institute, Brisbane, Queensland, Australia

${ }^{96}$ https://pcap.bioinf.unc.edu/

${ }^{97}$ http://impact.icr.ac.uk

${ }^{98} \mathrm{http}: / /$ www.cancerresearchuk.org/about-cancer/find-a-clinical-trial/a-study-find-outlooking-gene-changes-would-be-useful-in-screening-for-prostate-cancer-profile-pilot ${ }^{99}$ Prostate Cancer Association Group to Investigate Cancer Associated Alterations in the Genome Consortium (PRACTICAL, http://practical.icr.ac.uk/). Additional members of the consortium are provided in the Supplementary Information.

Funding: This study was funded in part by grants from the University of California (\#C21CR2060), the United States National Institute of Health/National Institute of Biomedical Imaging and Bioengineering (\#K08EB026503), the Prostate Cancer Foundation, the Research Council of Norway (\#223273), KG Jebsen Stiftelsen, and South East Norway Health Authority. Funding for the PRACTICAL consortium member studies is detailed in the Supplementary Information. The content is solely the responsibility of the authors and does not necessarily represent the official views of any of the funding agencies, who had no role in the design and conduct of the study; collection, management, analysis, and interpretation of the data; preparation, review, or approval of the manuscript; and decision to submit the manuscript for publication.

Competing interests: All authors declare no support from any organization for the submitted work except as follows: AMD and TMS report a past research grant from the US Department of Defense. OAA reports research grants from K.G Jebsen Stiftelsen, Research Council of Norway, and South East Norway Health Authority. Authors declare no financial relationships with any organizations that might have an interest in the submitted work in the previous three years except as follows, with all of these relationships outside the present study: TMS reports honoraria from Multimodal Imaging Services Corporation, Varian Medical Systems, and WebMD; he has an equity interest in CorTechs Labs and also serves on its Scientific Advisory Board. These companies might potentially benefit from the research results. The terms of this arrangement have been reviewed and approved by the University of California San Diego in accordance with its conflict-of-interest policies. OAA reports speaker honoraria from Lundbeck. Authors declare no other relationships or activities that could appear to have influenced the submitted work except as follows: OAA has a patent application \# U. S. 
medRxiv preprint doi: https://doi.org/10.1101/2021.08.14.21261931; this version posted August 18, 2021. The copyright holder for this preprint (which was not certified by peer review) is the author/funder, who has granted medRxiv a license to display the preprint in perpetuity. All rights reserved. No reuse allowed without permission.

20150356243 pending; AMD also applied for this patent application and assigned it to UC San Diego. AMD has additional disclosures outside the present work: founder, equity holder, and advisory board member for CorTechs Labs, Inc.; founder and equity holder in HealthLytix, Inc., advisory board member of Human Longevity, Inc.; recipient of nonfinancial research support from General Electric Healthcare. OAA is a consultant for HealthLytix, Inc. Additional acknowledgments for the PRACTICAL consortium and contributing studies are described in the Supplementary Information.

Ethics statement: The present analyses used de-identified data from the PRACTICAL consortium and have been approved by the Institutional Review Board at the University of California San Diego. All contributing studies were approved by the relevant ethics committees and performed in accordance with the Declaration of Helsinki. 


\section{Abstract}

Introduction: Prostate cancer risk stratification using single-nucleotide polymorphisms (SNPs) demonstrates considerable promise in men of European, Asian, and African genetic ancestries, but there is still need for increased accuracy. We evaluated whether including additional SNPs in a prostate cancer polygenic hazard score (PHS) would improve associations with clinically significant prostate cancer in multi-ancestry datasets.

Methods: In total, 299 SNPs previously associated with prostate cancer were evaluated for inclusion in a new PHS, using a LASSO-regularized Cox proportional hazards model in a training dataset of 72,181 men from the PRACTICAL Consortium. The PHS model was evaluated in four testing datasets: African ancestry, Asian ancestry, and two of European Ancestry - the Cohort of Swedish Men (COSM) and the ProtecT study. Hazard ratios (HRs) were estimated to compare men with high versus low PHS for association with clinically significant, with any, and with fatal prostate cancer. The impact of genetic risk stratification on the positive predictive value (PPV) of PSA testing for clinically significant prostate cancer was also measured.

Results: The final model (PHS290) had 290 SNPs with non-zero coefficients.

Comparing, for example, the highest and lowest quintiles of PHS290, the hazard ratios (HRs) for clinically significant prostate cancer were 13.73 [95\% Cl: 12.43-15.16] in ProtecT, 7.07 [6.58-7.60] in African ancestry, 10.31 [9.58-11.11] in Asian ancestry, and 
medRxiv preprint doi: https://doi.org/10.1101/2021.08.14.21261931; this version posted August 18, 2021. The copyright holder for this preprint (which was not certified by peer review) is the author/funder, who has granted medRxiv a license to display the preprint in perpetuity.

All rights reserved. No reuse allowed without permission.

11.18 [10.34-12.09] in COSM. Similar results were seen for association with any and fatal prostate cancer. Without PHS stratification, the PPV of PSA testing for clinically significant prostate cancer in ProtecT was $0.12(0.11-0.14)$. For the top $20 \%$ and top $5 \%$ of PHS290, the PPV was $0.19(0.15-0.22)$ and $0.26(0.19-0.33)$, respectively.

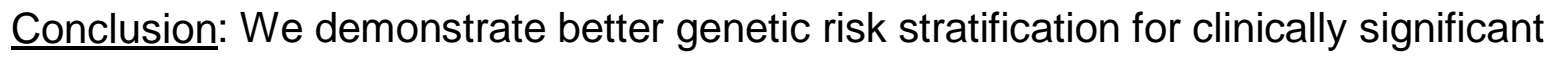
prostate cancer than prior versions of PHS in multi-ancestry datasets. This is promising for implementing precision-medicine approaches to prostate cancer screening decisions in diverse populations. 


\section{Introduction}

Identification of men at greatest risk of developing prostate cancer remains an important challenge. Risk stratification using common genetic markers, such as singlenucleotide polymorphisms (SNPs), shows promise toward more effectively identifying men at greatest risk of developing aggressive or fatal prostate cancer ${ }^{1,2}$. Analyses of benefit, harm, and cost-effectiveness support use of genomic risk stratification to guide prostate cancer screening ${ }^{3,4}$. Ensuring these tools perform well in diverse populations is important to ensure risk stratification is optimal for all men and avoid exacerbating existing health disparities ${ }^{5,6}$.

We previously developed a polygenic hazard score (PHS) and demonstrated in an independent European dataset that the PHS was associated with age at diagnosis of clinically significant prostate cancer ${ }^{1}$. Risk stratification with this score also improved the accuracy of PSA testing ${ }^{7,8}$. We then validated the PHS model (with 46 SNPs) for association with age at diagnosis and with prostate-cancer specific mortality in a dataset that included men of diverse descent, including European, African, and Asian ancestry ${ }^{2}$. We have also improved performance in men of African ancestry by searching for SNPs within that subpopulation ${ }^{9,10}$.

Recent meta-analyses have identified over 200 SNPs associated with prostate cancer, including some identified through subset analyses in men of non-European ancestry $^{11,12}$. Given the increasing number of SNPs associated with prostate cancer, we evaluated whether including more SNPs in a prostate cancer PHS would improve associations with clinically significant prostate cancer in multi-ancestry datasets. 


\section{Methods}

\section{Participants}

Genotype and phenotype data, all de-identified, were obtained from the PRACTICAL consortium. Participants had previously been genotyped via the OncoArray ${ }^{13}$ or the iCOGs ${ }^{14}$ chips; 90,638 men were available for this analysis.

The available data were split into a training dataset and four testing datasets, taking into account prior power analyses and PHS association results ${ }^{7,15,16}$. The training dataset for the model included 72,181 men of European genetic ancestry genotyped via OncoArray (24,010 controls and 48,171 cases). The four testing datasets included: 1$)$ men of African ancestry ( $n=6,253: 3,013$ controls and 3,240 cases), 2) men of Asian ancestry ( $n=2,378: 1,184$ controls and 1,194 cases), 3) the Cohort of Swedish Men (COSM) population-based cohort with long-term outcomes ${ }^{17}(n=3,279: 1,116$ controls, 2,163 cases, and 278 prostate cancer deaths), and 4) the ProtecT population-based prospective trial with screening (prostate-specific antigen, PSA) and biopsy outcomes for both cases and controls ( $n=6,411: 4,828$ controls and 1,583 cases $)^{18}$.

\section{Polygenic Hazard Score Model Development using LASSO regularization}

We sought to develop an optimal, integrated PHS model with candidate SNPS chosen from those used in the prior PHS and from those identified as susceptibility loci for prostate cancer in a genome-wide trans-ancestry meta-analysis ${ }^{11}$. Candidate SNPs included the 46 from the original PHS development and 269 from the meta-analysis. A machine-learning, LASSO-regularized Cox proportional hazards model approach was used to objectively select SNPs and estimate weights, as described previously ${ }^{8}$. 
There were 299 unique candidate SNPs associated with prostate cancer consistent across the training and testing datasets used in the present work. We first identified SNP pairs (among the 299 candidates) that were highly correlated $\left(r^{2}>0.95\right)$. Each of these paired, correlated SNPs was tested in a univariable Cox proportional hazards model for association with age at prostate cancer diagnosis; the SNP with the larger $p$-value was eliminated from inclusion in the model. All other (unpaired) SNPs were included as candidates for the present PHS model.

The $R$ (version 4.0.1) "glmnet" package was used to estimate the LASSOregularized Cox proportional hazards mode $\left.\right|^{19,20}$. Age at prostate cancer diagnosis was the time to event, and the predictor variables included the genotype allele counts of candidate SNPs and first four European ancestry principal components. Controls were censored at age of last follow-up. The LASSO-regularized model's hyper-parameter (lambda) was selected using 10-fold cross-validation ${ }^{19,20}$. The final form of the LASSO model was estimated using the lambda value that minimized the mean cross-validated error.

\section{Association with Prostate Cancer}

We evaluated the association of the adapted PHS with clinically significant prostate cancer, as well as any prostate cancer, via Cox proportional hazards models in each of the four testing datasets. Clinically significant prostate cancer was defined to be a prostate cancer case with Gleason score $\geq 7, \mathrm{PSA} \geq 10 \mathrm{ng} / \mathrm{mL}$, T3-T4 stage, nodal metastases, or distant metastases ${ }^{21}$. 
As the COSM dataset had long-term follow up data available ${ }^{17}$, we additionally evaluated the adapted PHS for association with age at prostate cancer death ${ }^{16}$. There were 278 deaths from prostate cancer in the COSM dataset.

\section{Hazard Ratio Performance}

Hazard ratios between the top 5\% and middle $40 \%\left(\mathrm{HR}_{95 / 50}\right)$, top $20 \%$ and middle $40 \%$ (HR80/50), bottom $20 \%$ and middle $40 \%\left(\mathrm{HR}_{20 / 50}\right)$, and top and bottom $20 \%\left(\mathrm{HR}_{80 / 20}\right)$ were estimated for any, for clinically significant, and for fatal prostate cancer. Percentiles of genetic risk were determined within the controls the training set with age less than 70 years ${ }^{1,2,7,8}$.

\section{Family History}

Given that family history of prostate cancer is currently one of the most useful clinical risk factors for the development of prostate cancer, we used Cox proportional hazards models to assess family history for association with any, with clinically significant, or with fatal prostate cancer. Family history of prostate cancer was defined as presence or absence of a first-degree relative diagnosed with prostate cancer. Multivariable models using both family history and the adapted PHS were compared to using family history alone via a log-likelihood test with $\alpha=0.01$. HRs were calculated for each variable: HRs for PHS in the multivariable models were estimated as the $\mathrm{HR}_{80 / 20}$ in each testing dataset (e.g., men in the highest vs. lowest quintile of genetic risk by PHS). HRs for family history of prostate cancer were estimated as the exponent of the beta 
from the multivariable Cox regression. As done previously ${ }^{1,7}, p$-values were truncated at $<10^{-16}$.

\section{Positive Predictive Value Performance}

Positive predictive value (PPV) performance of PSA testing was calculated using data from the population-based ProtecT screening study ${ }^{18}$ (prostate biopsy results were available for both cases and controls with a positive PSA [ $\geq 3 \mathrm{ng} / \mathrm{mL}])$. To estimate the PPV and confidence intervals, we generated 1,000 bootstrap samples using Protec T participants with positive PSA, while maintaining the 1:2 case:control ratio in the ProtecT dataset. PPV was calculated as the proportion of PSA-positive participants who were diagnosed with clinically significant prostate cancer on biopsy, looking at those participants in the top $5\left(\mathrm{PPV}_{95}\right)$ or top 20 percentiles $\left(\mathrm{PPV}_{80}\right)$ of $\mathrm{PHS}$ genetic risk.

\section{Cumulative incidence curves for PHS}

Genetic-risk-stratified cumulative incidence curves for prostate cancer were derived using previously described methods ${ }^{7,8}$. Briefly, age-specific population data from the United Kingdom (Cancer Research $\mathrm{UK}^{7}$ ) were used to estimate prostate cancer incidence for men aged 40-70 years. Data from the population-based Cluster Randomized Trial of PSA Testing for Prostate Cancer (CAP) trial ${ }^{7}$ were used to adjust this population incidence curve to reflect the age-specific cumulative incidence of clinically significant and non-clinically-significant prostate cancer. Genetic-risk-stratified cumulative incidence curves were then calculated for men in the upper 5 and 20 
percentiles of PHS genetic risk by multiplying the prostate-cancer-specific cumulative incidence by the mean value of $\mathrm{HR}_{95 / 50}$ and $\mathrm{HR}_{80 / 50}$ in the testing dataset, respectively.

\section{Results}

A total of 290 SNPs returned non-zero SNP coefficients using the regularizationweight selection and were included in the final model, called PHS290 (Supplementary Material).

HR performance of PHS290 demonstrates risk stratification across percentiles of genetic risk (Table 1). Comparing the top and bottom quintiles of genetic risk for clinically significant prostate cancer, men with high PHS had HRs of 13.73 [12.4315.16], 7.07 [6.58-7.60], 10.31 [9.58-11.11], and 11.18 [10.34-12.09] in the ProtecT, African, Asian, and COSM datasets, respectively. Similar risk stratification was seen when evaluating risk of any prostate cancer. Finally, when comparing the top and bottom quintiles of genetic risk in the COSM dataset, men with high PHS had a HR of $7.73[6.45-9.27]$ for prostate cancer death.

\section{Family history and PHS290}

The combination of family history and PHS performed better than family history, alone, for clinically significant prostate cancer (and for any prostate cancer) in each of the four testing datasets (log-likelihood $p<10^{-16}$; Table 2). Additionally, family history and PHS together performed better than family history, alone, for fatal prostate cancer in the COSM dataset $\left(\log\right.$-likelihood $\left.p<{ }^{10-16}\right)$. 
Positive predictive value performance of PHS290

The PPV of PSA testing for clinically significant prostate cancer was $0.19(0.15-$ $0.22)$ for the top $20 \%$ of genetic risk $\left(\mathrm{PPV}_{80}\right)$ and $0.26(0.19-0.33)$ for the top $5 \%$ of genetic risk $\left(\mathrm{PPV}_{80}\right.$; Figure 1). Both were greater than the overall PPV of PSA alone, which was $0.12(0.11-0.14)$.

Cumulative incidence curves for PHS290

Genetic-risk-stratified cumulative incidence curves for clinically significant and non-clinically significant prostate cancer demonstrate greater prostate cancer incidence with higher genetic-adjusted risk (Figure 2).

\section{Discussion}

The improved PHS (PHS290) demonstrates excellent genetic risk stratification, including for clinically significant prostate cancer. This was true in four separate testing sets of varied genetic ancestry (Asian, African, European). Additionally, PHS290 was associated with lifetime prostate-cancer-specific mortality in a population-based cohort $^{16}$. Hazard ratios with PHS290 are larger for each of these associations than those reported for previous versions of $\mathrm{PHS}^{2,8}$, demonstrating the value of incorporating SNPs from genome-wide meta-analysis and fine-mapping. The improvements demonstrated here are promising for implementing personalized approaches to prostate cancer screening decisions in diverse populations.

Health disparities are a major problem in prostate cancer. Given the exclusion of non-European data in most genome studies ${ }^{5,22-24}$, it is important that the pool of 
candidate SNPs here included those identified from a recent trans-ancestry metaanalysis $^{11}$. Testing and improving performance of genomic risk scores in diverse populations is critical to equitable implementation of these new tools and important for avoiding exacerbation of existing disparities. PHS290 still performs better in men of European genetic ancestry-an expected result, given the much greater data availability in that population. Further genomic studies in diverse populations are essential, as diversity in model development improves performance in diverse populations ${ }^{9,10}$.

The intersection of social constructs like race/ethnicity and genomics also raises interesting and entangled challenges. Even availability of genomic data is only part of the problem, as disparities in health outcomes are rooted in systemic racism and inequities in access to healthcare ${ }^{25,26}$. Genotypic ancestry may be a step toward biology, but the continental groups still represent an oversimplification of genetic diversity and a pre-determined assumption that socially defined categories have biological meaning in all contexts. We have previously shown that agnostic genetic clusters are informative for subgroup analyses ${ }^{2}$, and this approach may be a better way forward, provided the genomic diversity of the whole population is represented in the available data. Here, we have used genotypic ancestry to evaluate the potential differential performance in groups historically excluded from large-scale genomic studies. We also note that local ancestry may be a critical consideration in admixed populations. We have found previously that PHS performance can vary by the makeup of a region of the genome, beyond what is explained by global ancestry categories assigned for an individual's entire genome ${ }^{10}$. Despite these challenges and 
opportunities for future improvement, the current results demonstrate PHS290 does provide meaningful risk stratification in diverse datasets.

The cumulative incidence of clinically significant prostate cancer is heavily influenced by age-specific genetic risk, as demonstrated by genetic-risk-stratified cumulative incidence curves (Figure 2). As men with high PHS290 age, the incidence curve for clinically significant prostate cancer increases dramatically, prominently separating from the incidence for non-clinically-significant prostate cancer. This effect is driven by the high HR for clinically significant prostate cancer in these men, combined with increasing incidence specifically of more clinically significant cancers as men age $^{7,27}$. Furthermore, we found that risk stratification with PHS290 improved accuracy of PSA testing, as assessed by probability of a positive PSA test leading to a diagnosis of clinically significant cancer on biopsy. Consistent with a prior study ${ }^{8}$, this improvement in PPV of PSA testing was not better when using PHS290 than when using PHS46 in this dataset $^{2}$. PPV analyses in larger datasets could permit finer granularity for age-specific genetic risk to assess whether the increased HRs of PHS290 might translate to better performance of PSA testing than that achieved already with PHS46.

The HRs reported here suggest clinical relevance for PHS290. Predictive tools in routine clinical use for other diseases (e.g., breast cancer, diabetes, and cardiovascular disease) have reported HRs of approximately 1-3 for endpoints of interest ${ }^{28-31}$. Current guidelines recommend earlier and more frequent consideration of prostate cancer screening for men with a family history of prostate cancer or African ancestry, citing an elevated risk $28-80 \%$ above that of men without these risk factors ${ }^{32-34}$. Guidelines more strongly recommend earlier and more frequent screening in men with germline 
mutations in $B R C A 2$, which are rare but are estimated to infer up to 3-fold increased risk $^{33-35}$. In the present study, men in the top 20\% for PHS290 (compared to men with average risk) had HRs for clinically significant prostate cancer of approximately 2.8 to 3.9. For men in the top $5 \%$ for PHS290, those HRs increase to 4.3 to 6.9 , depending on ancestry. While individuals with high polygenic risk may also develop low-grade prostate cancer in their lifetime, the time-to-event analysis applied here shows that high genetic risk confers a greater hazard for prostate cancer death. This finding is consistent with prior reports, though the effect size is larger with $\mathrm{PHS} 290^{2,16,33}$.

Our work has some limitations. First, the weights were calculated in men of European genetic ancestry alone, although SNP candidate selection was performed in multi-ancestry analyses. Future studies evaluating PHS for prostate cancer risk stratification will include non-Europeans in SNP weight calculations. The available data did not permit testing of PPV or association with fatal disease in non-European populations. Moreover, the cumulative incidence curves here are specific to the UK, where we had the most robust population age-specific incidence data for clinically significant prostate cancer. The testing sets used in the present study did represent a very small proportion of the data used for candidate SNP identification in the prior genome-wide association meta-analysis (as opposed to the development of PHS46, which was performed in a dataset completely independent of the validation dataset) ${ }^{211}$. However, the training and testing sets were kept separate in the present study, and the use of the LASSO-regularized Cox model reduces over-fitting ${ }^{36}$.

The PHS290 described here has the strongest reported association with prostate cancer in men of European, African, and Asian genetic ancestry. The score was also 
medRxiv preprint doi: https://doi.org/10.1101/2021.08.14.21261931; this version posted August 18, 2021. The copyright holder for this preprint (which was not certified by peer review) is the author/funder, who has granted medRxiv a license to display the preprint in perpetuity.

All rights reserved. No reuse allowed without permission.

associated with lifetime prostate-cancer-specific mortality in a population-based cohort.

A performance gap remains between genetic ancestry groups that might be closed through development using more data from men of Asian or African ancestry.

Nonetheless, the results here suggest PHS290 may improve prostate cancer riskstratification efforts in multi-ancestry populations. 


\section{References}

1. Seibert, T. M. et al. Polygenic hazard score to guide screening for aggressive prostate cancer: Development and validation in large scale cohorts. BMJ (Online) 360, 1-7 (2018).

2. Huynh-Le, M.-P. et al. Polygenic hazard score is associated with prostate cancer in multi-ethnic populations. Nature Communications 12, 1236 (2021).

3. Callender, T., Emberton, M., Morris, S., Pharoah, P. D. P. \& Pashayan, N. Benefit, Harm, and Cost-effectiveness Associated with Magnetic Resonance Imaging before Biopsy in Age-based and Risk-stratified Screening for Prostate Cancer. JAMA Network Open 4, 2037657 (2021).

4. Callender, T. et al. Polygenic risk-tailored screening for prostate cancer: A benefitharm and cost-effectiveness modelling study. PLoS Medicine 16, e1002998 (2019).

5. Petrovski, S. \& Goldstein, D. B. Unequal representation of genetic variation across ancestry groups creates healthcare inequality in the application of precision medicine. Genome Biology 17, (2016).

6. Duncan, L. et al. Analysis of polygenic risk score usage and performance in diverse human populations. Nature Communications 10, (2019).

7. Huynh-Le, M. P. et al. A genetic risk score to personalize prostate cancer screening, applied to population data. Cancer Epidemiology Biomarkers and Prevention 29, 1731-1738 (2020).

8. Karunamuni, R. A. et al. Additional SNPs improve risk stratification of a polygenic hazard score for prostate cancer. Prostate Cancer and Prostatic Diseases (2021) doi:10.1038/s41391-020-00311-2. 
9. Karunamuni, R. A. et al. African $\square$ specific improvement of a polygenic hazard score for age at diagnosis of prostate cancer. International Journal of Cancer 148, 99-105 (2021).

10. Karunamuni, R. A. et al. Performance of African-ancestry-specific polygenic hazard score varies according to local ancestry in $8 q 24$. Prostate Cancer and Prostatic Diseases 1-9 (2021) doi:10.1038/s41391-021-00403-7.

11. Conti, D. V. et al. Trans-ancestry genome-wide association meta-analysis of prostate cancer identifies new susceptibility loci and informs genetic risk prediction. Nature Genetics 53, 65-75 (2021).

12. Schumacher, F. R. et al. Association analyses of more than 140,000 men identify 63 new prostate cancer susceptibility loci. Nature Genetics 50, 928-936 (2018).

13. Amos, C. I. et al. The OncoArray consortium: A network for understanding the genetic architecture of common cancers. Cancer Epidemiology Biomarkers and Prevention 26, 126-135 (2017).

14. Eeles, R. A. et al. Identification of 23 new prostate cancer susceptibility loci using the iCOGS custom genotyping array. Nature Genetics 45, 385-391 (2013).

15. Karunamuni, R. A. et al. The effect of sample size on polygenic hazard models for prostate cancer. European Journal of Human Genetics (2020) doi:10.1038/s41431020-0664-2.

16. Huynh-Le, M.-P. et al. Common genetic and clinical risk factors: association with fatal prostate cancer in the Cohort of Swedish Men. Prostate Cancer and Prostatic Diseases 1-7 (2021) doi:10.1038/s41391-021-00341-4. 
17. Discacciati, A. et al. Coffee consumption and risk of localized, advanced and fatal prostate cancer: a population-based prospective study. Annals of Oncology 24, 1912-1918 (2013).

18. Hamdy, F. C. et al. 10-Year Outcomes after Monitoring, Surgery, or Radiotherapy for Localized Prostate Cancer. New England Journal of Medicine 375, 1415-1424 (2016).

19. Tibshirani, R. The lasso method for variable selection in the cox model. Statistics in Medicine 16, 385-395 (1997).

20. Tibshirani, R. Regression Shrinkage and Selection via the Lasso. J R Stat Soc $B$ 267-88 (1996).

21. Schaeffer, E. et al. Prostate cancer, version 1.2021: Featured updates to the nccn guidelines. JNCCN Journal of the National Comprehensive Cancer Network 19, 134-143 (2021).

22. Martin, A. R. et al. Clinical use of current polygenic risk scores may exacerbate health disparities. Nature Genetics 51, 584-591 (2019).

23. Grinde, K. E. et al. Generalizing polygenic risk scores from Europeans to Hispanics/Latinos. Genetic Epidemiology 43, 50-62 (2019).

24. Popejoy, A. B. \& Fullerton, S. M. Genomics is failing on diversity. Nature vol. 538 161-164 (2016).

25. Riviere, P. et al. Survival of African American and non-Hispanic white men with prostate cancer in an equal-access health care system. Cancer 126, 1683-1690 (2020). 
26. Dess, R. T. et al. Association of Black Race with Prostate Cancer-Specific and Other-Cause Mortality. JAMA Oncology 5, 975-983 (2019).

27. Huynh-Le, M. P. et al. Age dependence of modern clinical risk groups for localized prostate cancer-A population-based study. Cancer 126, 1691-1699 (2020).

28. Brentnall, A. R., Cuzick, J., Buist, D. S. M. \& Bowles, E. J. A. Long-term Accuracy of Breast Cancer Risk Assessment Combining Classic Risk Factors and Breast Density. JAMA Oncol 4, e180174 (2018).

29. Torkamani, A., Wineinger, N. E. \& Topol, E. J. The personal and clinical utility of polygenic risk scores. Nature Reviews Genetics 1 (2018) doi:10.1038/s41576-0180018-x.

30. Yeh, H.-C., Duncan, B. B., Schmidt, M. I., Wang, N.-Y. \& Brancati, F. L. Smoking, smoking cessation, and risk for type 2 diabetes mellitus: a cohort study. Ann Intern Med 152, 10-17 (2010).

31. Wang, T. J. et al. Plasma natriuretic peptide levels and the risk of cardiovascular events and death. N Engl J Med 350, 655-663 (2004).

32. Tsodikov, A. et al. Is prostate cancer different in black men? Answers from 3 natural history models. Cancer 123, 2312-2319 (2017).

33. Shi, Z. et al. Performance of Three Inherited Risk Measures for Predicting Prostate Cancer Incidence and Mortality: A Population-based Prospective Analysis. European Urology (2020) doi:10.1016/j.eururo.2020.11.014.

34. Carroll, P. R. et al. NCCN Guidelines Prostate Cancer Early Detection Version 1.2021. (2021). 
medRxiv preprint doi: https://doi.org/10.1101/2021.08.14.21261931; this version posted August 18, 2021. The copyright holder for this preprint (which was not certified by peer review) is the author/funder, who has granted medRxiv a license to display the preprint in perpetuity.

All rights reserved. No reuse allowed without permission.

35. Giri, V. N. et al. Implementation of Germline Testing for Prostate Cancer:

Philadelphia Prostate Cancer Consensus Conference 2019. JCO JCO.20.00046 (2020) doi:10.1200/JCO.20.00046.

36. McNeish, D. M. Using Lasso for Predictor Selection and to Assuage Overfitting: A

Method Long Overlooked in Behavioral Sciences. Multivariate Behavioral Research

50, 471-484 (2015). 
medRxiv preprint doi: https://doi.org/10.1101/2021.08.14.21261931; this version posted August 18, 2021. The copyright holder for this preprint (which was not certified by peer review) is the author/funder, who has granted medRxiv a license to display the preprint in perpetuity.

All rights reserved. No reuse allowed without permission.

Table 1. Hazard ratio (HR) performance in the four testing datasets. HRs are shown with mean sample-weight-corrected values and $95 \%$ confidence intervals. Calculations were done using age at diagnosis of any or of clinically significant prostate cancer across all datasets, respectively, and also with age at prostate cancer death for the COSM dataset.

\begin{tabular}{|c|c|c|c|c|c|}
\hline \multirow{2}{*}{ Dataset } & \multirow{2}{*}{$\begin{array}{c}\text { Prostate Cancer } \\
\text { Type }\end{array}$} & \multicolumn{4}{|c|}{ HRs and $95 \% \mathrm{Cl}$} \\
\hline & & $\mathrm{HR}_{20 / 50}$ & $\mathrm{HR}_{80 / 50}$ & $\mathrm{HR}_{95 / 50}$ & $\mathrm{HR}_{80 / 20}$ \\
\hline \multirow{2}{*}{$\begin{array}{l}\text { ProtecT } \\
n=6,411\end{array}$} & Any & $0.31[0.30-0.32]$ & 3.47 [3.36-3.58] & $5.93[5.67-6.21]$ & $11.16[10.48-11.88]$ \\
\hline & Clinically significant & $0.28[0.27-0.30]$ & $3.86[3.67-4.06]$ & $6.91[6.42-7.44]$ & $13.73[12.43-15.16]$ \\
\hline \multirow{2}{*}{$\begin{array}{c}\text { African } \\
\mathrm{n}=6,253\end{array}$} & Any & $0.43[0.42-0.45]$ & $2.58[2.50-2.67]$ & $3.69[3.52-3.86]$ & $5.95[5.59-6.34]$ \\
\hline & Clinically significant & $0.40[0.39-0.41]$ & $2.82[2.72-2.93]$ & $4.33[4.10-4.57]$ & $7.07[6.58-7.60]$ \\
\hline \multirow{2}{*}{$\begin{array}{c}\text { Asian } \\
n=2,378\end{array}$} & Any & $0.34[0.33-0.35]$ & $2.99[2.89-3.08]$ & $5.08[4.85-5.33]$ & $8.75[8.21-9.32]$ \\
\hline & Clinically significant & $0.31[0.30-0.33]$ & $3.24[3.12-3.36]$ & $5.66[5.46-5.98]$ & $10.31[9.58-11.11]$ \\
\hline \multirow{3}{*}{$\begin{array}{c}\text { COSM } \\
n=3,279\end{array}$} & Any & $0.33[0.32-0.34]$ & 3.54 [3.42-3.65] & $5.77[5.51-6.04]$ & $10.87[10.21-11.57]$ \\
\hline & Clinically significant & $0.32[0.31-0.33]$ & 3.59 [3.45-3.75] & $5.91[5.58-6.26]$ & $11.18[10.34-12.09]$ \\
\hline & Fatal & $0.38[0.35-0.42]$ & 2.95 [2.68-3.25] & $4.49[3.93-5.13]$ & $7.73[6.45-9.27]$ \\
\hline
\end{tabular}


medRxiv preprint doi: https://doi.org/10.1101/2021.08.14.21261931; this version posted August 18, 2021. The copyright holder for this preprint (which was not certified by peer review) is the author/funder, who has granted medRxiv a license to display the preprint in perpetuity.

All rights reserved. No reuse allowed without permission.

Table 2. Multivariable Cox models with both PHS and family history of prostate cancer (defined as $\geq 1$ first-degree relative affected) for association with any prostate cancer, with clinically significant prostate cancer, and with fatal prostate cancer. Analyses were limited to participants with known family history. Beta and $z$-scores refer to the overall association (within the multivariable Cox regression) with the endpoint of interest, within the corresponding testing dataset. The $p$-values reported are two-tailed from the multivariable Cox models.

\begin{tabular}{|c|c|c|c|c|c|}
\hline \multirow{2}{*}{ Dataset } & \multirow{2}{*}{ Variable } & \multicolumn{4}{|c|}{ Any Prostate Cancer } \\
\hline & & beta & z-score & p-value & HR \\
\hline \multirow{2}{*}{$\begin{array}{c}\text { ProtecT (iCOGs), } \\
n=5,703\end{array}$} & PHS & 2.11 & 72.1 & $<10^{-16}$ & 8.13 \\
\hline & Family history & 0.06 & 1.7 & 0.1 & 1.07 \\
\hline \multirow{2}{*}{$\begin{array}{l}\text { African (OncoArray), } \\
\qquad n=5,557\end{array}$} & PHS & 1.64 & 53.8 & $<10^{-16}$ & 5.03 \\
\hline & Family history & 1.13 & 46.6 & $<10^{-16}$ & 3.09 \\
\hline \multirow{2}{*}{$\begin{array}{c}\text { Asian (OncoArray); } \\
n=1,028\end{array}$} & PHS & 1.99 & 68.5 & $<10^{-16}$ & 7.64 \\
\hline & Family history & 0.45 & 13.1 & $<10^{-16}$ & 1.56 \\
\hline \multirow{2}{*}{$\begin{array}{c}\text { COSM (OncoArray), } \\
n=2,453\end{array}$} & PHS & 2.13 & 71.2 & $<10^{-16}$ & 8.71 \\
\hline & Family history & 0.53 & 19.0 & $<10^{-16}$ & 1.70 \\
\hline \multirow{2}{*}{ Dataset } & \multirow{2}{*}{ Variable } & \multicolumn{4}{|c|}{ Clinically Significant Prostate Cancer } \\
\hline & & beta & z-score & p-value & HR \\
\hline \multirow{2}{*}{$\begin{array}{c}\text { ProtecT (iCOGs), } \\
n=5,703\end{array}$} & PHS & 2.32 & 49.8 & $<10^{-16}$ & 10.01 \\
\hline & Family history & -0.01 & -0.2 & 0.82 & 0.99 \\
\hline \multirow{2}{*}{$\begin{array}{c}\text { African (OncoArray), } \\
n=5,557\end{array}$} & PHS & 1.67 & 37.4 & $<10^{-16}$ & 5.19 \\
\hline & Family history & 1.17 & 33.2 & $<10^{-16}$ & 3.22 \\
\hline \multirow{2}{*}{$\begin{array}{c}\text { Asian (OncoArray), } \\
n=1,028\end{array}$} & PHS & 1.89 & 50.4 & $<10^{-16}$ & 6.90 \\
\hline & Family history & 0.13 & 2.5 & 0.012 & 1.14 \\
\hline \multirow{2}{*}{$\begin{array}{c}\text { COSM (OncoArray), } \\
n=2,453\end{array}$} & PHS & 2.13 & 56.9 & $<10^{-16}$ & 6.90 \\
\hline & Family history & 0.45 & 12.6 & $<10^{-16}$ & 1.57 \\
\hline \multirow{2}{*}{ Dataset } & \multirow{2}{*}{ Variable } & \multicolumn{4}{|c|}{ Fatal Prostate Cancer } \\
\hline & & beta & z-score & p-value & HR \\
\hline
\end{tabular}


medRxiv preprint doi: https://doi.org/10.1101/2021.08.14.21261931; this version posted August 18, 2021. The copyright holder for this preprint (which was not certified by peer review) is the author/funder, who has granted medRxiv a license to display the preprint in perpetuity.

All rights reserved. No reuse allowed without permission.

cosm (OncoArray), $\mathrm{n}=2,453$
PHS

Family history
1.68

0.43
19.8

5.0


medRxiv preprint doi: https://doi.org/10.1101/2021.08.14.21261931; this version posted August 18, 2021. The copyright holder for this preprint (which was not certified by peer review) is the author/funder, who has granted medRxiv a license to display the preprint in perpetuity.

All rights reserved. No reuse allowed without permission.

Figure 1. PPV performance in the ProtecT dataset for clinically significant prostate cancer, estimated using 3 approaches: standard (not using PHS), top 20\% of PHS values (PPV80), and top 5\% of PHS values (PPV95). Error bars are $95 \%$ bootstrap confidence intervals.

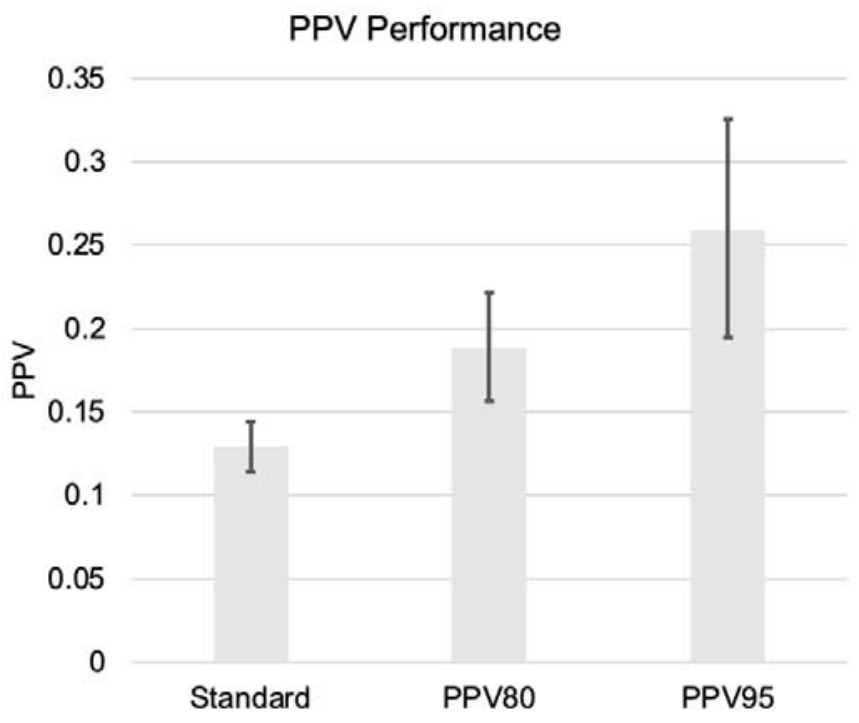


Figure 2. Genetic-risk-adjusted cumulative incidence curves for PHS290. Curves are shown for the upper $5^{\text {th }}\left(>95^{\text {th }}\right)$ and upper $20^{\text {th }}\left(>80^{\text {th }}\right)$ percentile of PHS290 for clinically significant and non-clinically-significant prostate cancer. The reference curves represent the overall population average from the UK.

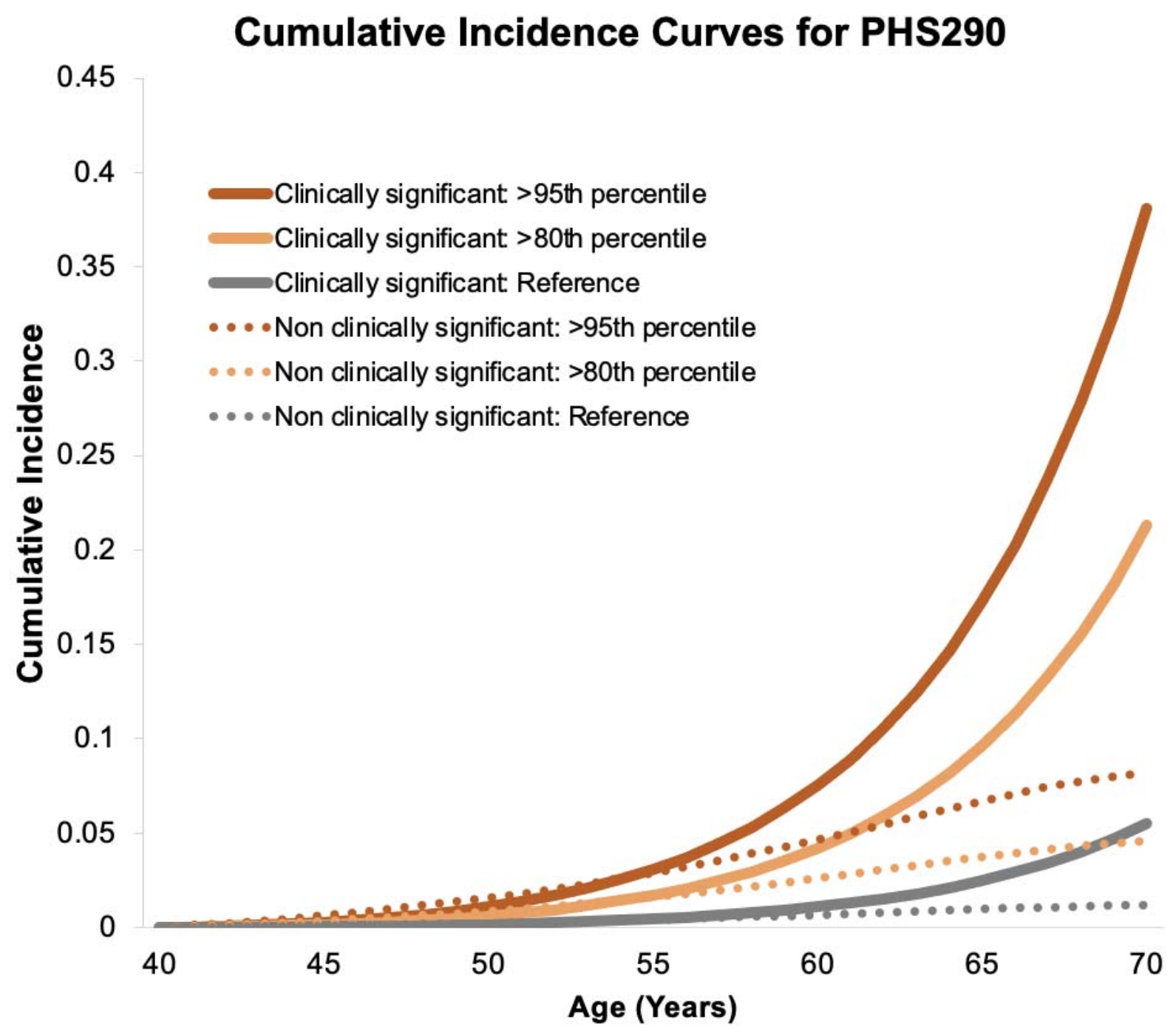


medRxiv preprint doi: https://doi.org/10.1101/2021.08.14.21261931; this version posted August 18, 2021. The copyright holder for this preprint (which was not certified by peer review) is the author/funder, who has granted medRxiv a license to display the preprint in perpetuity.

All rights reserved. No reuse allowed without permission. 